\title{
MANIFESTAÇÕES CLÍNICAS E FONOAUDIOLÓGICAS NA SÍNDROME DE TURNER: ESTUDO BIBLIOGRÁFICO
}

\section{Clinical and speech, hearing and language pathology manifestations on Turner Syndrome : bibliographical study}

\author{
Suhamy Aline Mandelli (1), Dagma Venturini Marques Abramides(2)
}

\section{RESUMO}

Tema: síndrome genética e achados fonoaudiológicos. Objetivo: descrever as manifestações clínicas e fonoaudiológicas em indivíduos com a Síndrome de Turner. Conclusão: foram levantados 23 artigos sobre a Síndrome de Turner dos quais 7 discorriam sobre a audição e suas alterações nesses indivíduos, 6 sobre linguagem receptiva e/ou expressiva e praxia, 5 sobre aspectos psicológicos e cognitivos além de 28 artigos referentes `as manifestações clínicas em geral. Por meio do levantamento bibliográfico pode-se observar que as manifestações fonoaudiológicas na Síndrome de Turner são pouco estudadas e, dentro da fonoaudiologia as manifestações audiológicas como perda de audição e otites são as mais estudadas, ao contrário dos aspectos práxicos e de recepção/ expressão da linguagem.

DESCRITORES: Síndrome de Turner; Linguagem ; Revisão

\section{INTRODUÇÃO}

As características da Síndrome de Turner (ST) foram descritas inicialmente por Bonnevie (1934) e Ullrich (1930), e Rossle em 1922 relatou a síndrome como nanismo de origem sexual ${ }^{1}$. Em 1938, a mesma condição foi descrita por Henry Turner porém, com caracterização mais detalhada. A expressão clínica da ST é variável, mas as alterações mais freqüentes são: a baixa estatura, imaturidade do desenvolvimento sexual, pescoço curto na infância, anomalias renais e cardiovasculares ${ }^{2}$.

O fenótipo também inclui anomalias somáticas como face triangular, nariz pequeno, baixa implantação de cabelo ${ }^{3}$ além de tórax escavatum. Alterações específicas visuais estão presentes (ptose, estrabismo, catarata, nistagmo e miopia) bem como audiológicas (lóbulo proeminente, otite média e perda auditiva do tipo neurossensorial) e relativas à cavidade oral (palato ogival ${ }^{4}$, mandíbula pequena e má-oclusão dentária) ${ }^{5}$. O fenótipo inclui um complexo craniofacial de pequeno comprimento

(1) Graduanda do curso de Fonoaudiologia da Faculdade de Odontologia de Bauru - FOB-USP.

(2) Professora Doutora do Departamento de Fonoaudiologia da Faculdade de Odontologia de Bauru - FOB-USP.

Conflito de interesses: inexistente posterior e aumentado ângulo da base do crânio assim como retrognatismo ${ }^{6}$. Alem disto, está associada a diversas morbidades em conseqüência das anomalias congênitas, das doenças mais prevalentes, da falta de tratamento ou do próprio tratamento e envelhecimento.

A ST acomete 1:1800 a 1:5000 recém-nascidos do sexo feminino ${ }^{(6)}$, sendo confirmada pela presença de um cromossomo $X$ e deleção total ou parcial do segundo cromossomo sexual em pacientes fenotipicamente feminino, com uma ou mais características clínicas atribuídas à síndrome. Ainda que tradicionalmente se considere o cariótipo $45, X$ como a mais prevalente, em torno de $50 \%$ dos casos, o aumento do número de células contadas em cariótipos ou a avaliação de outros tecidos demonstra uma freqüência maior de indivíduos com mosaicismo $^{7}$.

Portanto, o diagnóstico é feito por meio do estudo cromossômico, com a presença de cariótipo de monossomia do cromossomo sexual (45 X ou $45 \mathrm{XO}$ ), associado com a perda de um cromossomo sexual $X$ ou $Y$, sendo que $1 / 3$ das pacientes são diagnosticadas no período neonatal, $1 / 3$ na infância e as restantes na puberdade, quando são observadas amenorréia e ausência de desenvolvimento sexual, juntamente com outras anomalias. 
No exame de cariótipo usualmente utiliza-se o sangue periférico. Quanto maior a contagem de células, maior a chance de identificação de linhagens em mosaicismo. Uma contagem rotineira com avaliação de 40 metáfases, utilizando técnicas de bandeamento cromossômico, detecta $8 \%$ de mosaicismo com limite de confiança de $95 \%$. Se houver suspeita clínica e cariótipo 46, XX em sangue periférico deve-se considerar a análise de outros tecidos visando à identificação de mosaicismo. Marcadores, quando presentes, na avaliação cariotípica devem ser caracterizados, utilizando, quando necessário, técnicas moleculares como hibridação in situ por fluorecência (FISH) ou reação em cadeia por polimerase (PCR). Há relatos de pacientes com cariótipo 45,X em linfócitos de sangue periférico com seqüências $Y$ específicas, descobertas por meios de avaliação molecular no mesmo tecido, associadas à presença de gonadoblastomas e disgerminomas gonadais, tornam indispensáveis a utilização destas técnicas em pacientes sem mosaicismo aparente.

Torna-se importante a pesquisa de mosaicos e particularmente da linha celular $X Y$, visto estes doentes apresentarem risco aumentado (15-25\%) de tumores das gônadas.

O diagnóstico também pode ser realizado no período pré-natal com cariótipo obtido a partir da amostra de vilocorial ou por meio de amniocentese e tem risco de perda fetal de $0,5 \%$ a $1 \%$. Quando indicada, a biópsia é o exame de escolha para o final do $1^{\circ}$ trimestre, enquanto a amniocentese deve ser realizada mais tardiamente na gestação ${ }^{8}$. Estudos têm revelado que, depois de realizada a suspeita pré-natal de ST, alguns pais tendem a realizar uma interrupção provocada da gestação. No entanto, podem ocorrer três desdobramentos dessa situação: o achado pré-natal de um cariótipo com linhagem 45,X nem sempre é confirmado no cariótipo pós-natal; as pacientes diagnosticadas incidentalmente em cariótipo prénatal têm uma maior proporção de mosaicismo, que dilui as características da síndrome e; ainda que com algumas limitações impostas pela ST, os fetos nascidos vivos são, na maioria das vezes, viáveis e sem impedimentos para uma inserção adequada e produtiva na sociedade ${ }^{9}$.

O tratamento para a ST consiste em reposições hormonais. Segundo pesquisas ${ }^{10}$, o tratamento a longo prazo com GH ("Growth Hormone", Hormônio do crescimento ou Somatotrofina, o qual é um hormônio sintetizado e secretado pela glândula hipófise anterior e, é responsável pelo estímulo ao crescimento e a reprodução celulares em humanos) aumenta a altura destes indivíduos sendo que o fator que mais influencia este ganho da altura é a idade do início do tratamento.

No estudo de Guimarães et al. ${ }^{11}$, apenas cinco dos 60 indivíduos estudados não apresentavam malformações congênitas e 55 apresentavam doenças associadas. Segundo Gravholt ${ }^{12}$ (1998) as mulheres com ST parecem apresentar maior número de fraturas devido a osteoporose na idade adulta e, no período da infância, a incidência de diabetes mellitus é alta, assim como isquemia e hipertensão. Dessa forma, o tratamento realizado por equipe multidisciplinar proporciona melhor qualidade de vida para esta população, a fim de contemplar os vários comprometimentos ${ }^{9}$.

O objetivo do presente trabalho é descrever as manifestações fonoaudiológicas na ST, a partir da coleta de informações de estudos já publicados sobre a temática pela comunidade científica nacional e internacional.

\section{MÉTODO}

Partindo da revisão bibliográfica, foi realizado estudo da literatura específica publicada entre os anos de início da descrição da síndrome 1938 a 2009. O levantamento bibliográfico foi realizado por meio de pesquisa em bases de dados nacionais e internacionais: LILACS (Literatura LatinoAmericana e do Caribe em Ciências da Saúde), MEDLINE (MEDlars onLINE - Literatura Internacional) e Scielo (Scientific Eletronic Library Online), obedecendo aos seguintes critérios de inclusão:

- Artigos com informações sobre alterações de linguagem receptiva e expressiva na ST;

- Artigos com apresentação de resultados da investigação científica com grupos experimentais e grupos controle;

- Artigos com informações sobre as alterações de natureza práxica/articulatória;

- Trabalhos científicos concluídos, incluindo monografia, dissertação de mestrado e tese de doutorado.

A apresentação dos estudos segue ordenação numérica, obedecendo à ordem cronológica de publicação, facilitando a leitura das tabelas.

Na Figura 1 são apresentados os estudos selecionados, com respectivo ano de publicação e nomes dos autores que desenvolveram os trabaIhos com a ST enfocando as manifestações fonoaudiológicas, bem como o número de participantes sindrômicos avaliados em cada um deles.

A Figura 2 apresenta os estudos selecionados a ST e seus achados, enfocando os aspectos relacionados à audição.

Na Figura 3 são apresentados os estudos relacionados à praxia e linguagem receptiva e expressiva e os instrumentos usados para avaliá-los . 
A Figura 4 apresenta os resultados das avaliações psicológicas quanto ao desempenho cognitivo e comportamental, descritas por estudo.
A Figura 5 apresenta os resultados das avaliações de linguagem receptiva (LR) e expressiva (LR), a partir das alterações encontradas, por estudo.

\begin{tabular}{|c|c|c|c|c|}
\hline Estudo & Ano & Título & Autores & $\begin{array}{c}\text { Número de Participantes } \\
\text { com a ST }\end{array}$ \\
\hline 1 & 1998 & $\begin{array}{l}\text { Otological problems in children } \\
\text { with Turner' syndrome }\end{array}$ & $\begin{array}{c}\text { Annika Elmqvist Stenberg, Olle } \\
\text { Nyllen, Marianne Windh e Malou } \\
\text { Hultcrantz } \\
\end{array}$ & 56 participantes \\
\hline 2 & 2002 & $\begin{array}{l}\text { Oral fluency and narrative } \\
\text { production in children with } \\
\text { Turner's syndrome }\end{array}$ & Christine M. Temple & $\begin{array}{l}19 \text { participantes } \\
20 \text { participantes como } \\
\text { grupo controle }\end{array}$ \\
\hline 3 & 2005 & $\begin{array}{c}\text { Functional dissociation of } \\
\text { amydala-modulated arousal and } \\
\text { cognitive appraisal, in Turner } \\
\text { syndrome }\end{array}$ & $\begin{array}{l}\text { D.H. Skuse, J.S. Morris e R. J. } \\
\text { Dolan }\end{array}$ & $\begin{array}{c}12 \text { pacientes monossômicas } \\
\text { para o gene } \mathrm{X} \text { e } \\
12 \text { pacientes controles }\end{array}$ \\
\hline 4 & 2006 & $\begin{array}{l}\text { Genomic Imprinting in Turner } \\
\text { syndrome: effects on response } \\
\text { to growth hormone and risk of } \\
\text { sensorioneural hearing loss }\end{array}$ & $\begin{array}{c}\text { Catherine E. Hamelin, Greg } \\
\text { Anglin, Charman A. Quisley e } \\
\text { Cheri L. Deal }\end{array}$ & 54 pacientes \\
\hline 5 & 2006 & $\begin{array}{c}\text { Estrogen and hearing: a } \\
\text { summary of recent investigations }\end{array}$ & $\begin{array}{c}\text { M.Hultcrantz, R.Simonoska e A } \\
\text {.E. Stenberg }\end{array}$ & Revisão bibliográfica \\
\hline 6 & 2006 & $\begin{array}{l}\text { Visuospatial executive function in } \\
\text { Turner syndrome: functional MRI } \\
\text { and neurocognitive-findings }\end{array}$ & $\begin{array}{c}\text { Sarah J. Hart, Marsha L. } \\
\text { Davenport, Stephen R. Hooper e } \\
\text { Aysenil Belger. }\end{array}$ & $\begin{array}{c}10 \text { participantes } \\
\text { monossômicas e } \\
15 \text { participantes do grupo } \\
\text { controle }\end{array}$ \\
\hline 7 & 2006 & $\begin{array}{l}\text { Language use in females with } \\
\text { Fragile X or Turner syndrome } \\
\text { during brief initial social } \\
\text { interactions }\end{array}$ & $\begin{array}{l}\text { Michele M. M.Mazzocco, Laurie } \\
\text { Thompson, Vicki Sudhalter, } \\
\text { Richard C. Belser, Katarzyna } \\
\text { Lesniak-Karpiak e Judith L. } \\
\text { Koss. }\end{array}$ & $\begin{array}{c}27 \text { pacientes com ST, } \\
20 \text { pacientes com Fra-X e } 28 \\
\text { pacientes no grupo controle. }\end{array}$ \\
\hline 8 & 2007 & $\begin{array}{l}\text { Fluency disorders in genetic } \\
\text { syndromes }\end{array}$ & $\begin{array}{l}\text { John Van Borsel e } \\
\text { John A. Tetnowski }\end{array}$ & $\begin{array}{l}128 \text { pacientes } \\
\text { revisão bibliográfica }\end{array}$ \\
\hline 9 & 2008 & $\begin{array}{l}\text { Evaluation of hearing organ in } \\
\text { patients with Turner syndrome }\end{array}$ & $\begin{array}{c}\text { Wojciech Gawron, Beata wikiera, } \\
\text { Beata Rostkowska-Nadolska, } \\
\text { Krystyna Orendorz-Fracz } \\
\text { Koviska e Anna Noczynska. } \\
\end{array}$ & $\begin{array}{c}29 \text { pacientes monossômicas } \\
\text { para o X e } 22 \text { com } \\
\text { mosaicismo. }\end{array}$ \\
\hline 10 & 2008 & $\begin{array}{c}\text { Language and Literacy in Turner } \\
\text { syndrome }\end{array}$ & Melissa M. Murphy & Revisão bibliográfica \\
\hline 11 & 2009 & Hearing loss in Turner syndrome & Monique Parkin e Paul Walker & 23 participantes \\
\hline 12 & 2009 & $\begin{array}{l}\text { Mathematical learning disability } \\
\text { in girls with Turner syndrome: a } \\
\text { challenge to defining MLD and } \\
\text { its subtypes }\end{array}$ & Michelle M. M. Mazzocco & Revisão bibliográfica \\
\hline 13 & 2009 & $\begin{array}{l}\text { Morphology studies of the } \\
\text { human fetal cochlea in Turner } \\
\text { syndrome }\end{array}$ & $\begin{array}{c}\text { John H. Fish III, Ilona } \\
\text { Schwentner, Joachim } \\
\text { Schmutzhard,Irene Abraham, } \\
\text { Andrea Ciorba, Alessandro } \\
\text { Martini, Consolato Segi, Annelise } \\
\text { Scrott-Fischer e Rudolf } \\
\text { Glueckert. } \\
\end{array}$ & $\begin{array}{l}\quad 9 \text { fetos com ST e } 4 \\
\text { ossos Temporais de fetos } \\
\text { como controle. }\end{array}$ \\
\hline 14 & 2009 & $\begin{array}{c}\text { Surgical management of otologic } \\
\text { disease in pediatric patients with } \\
\text { Turner syndrome }\end{array}$ & $\begin{array}{l}\text { Joseph E. Hall, Greshan T. } \\
\text { Richter e Daniel I. Choo }\end{array}$ & 178 pacientes \\
\hline 15 & 2009 & $\begin{array}{l}\text { Effects of Estrogen on Nonverbal } \\
\text { Processing Speed and Motor } \\
\text { Function in Girls with Turners } \\
\text { Syndrome }\end{array}$ & $\begin{array}{l}\text { Judith L. Ross, David Roeltgen, } \\
\text { Penelope Feuillan, Harvey } \\
\text { Kushner e Gordon B. Cutler, Jr. }\end{array}$ & 47 pacientes \\
\hline
\end{tabular}

Figura 1- Estudos, ano de publicação, autores e número de participantes com a ST 


\begin{tabular}{|c|c|}
\hline ESTUDO & RESULTADOS \\
\hline 1 & $\begin{array}{l}\text { - A alta incidência da otite média aguda recorrente nas ST com patologia no tímpano se } \\
\text { revelaram uma sequela frequente. } \\
\text { - A alta prevalência ( } 61 \% \text { ) da otite média aguda recorrente foi achada nesse estudo e } 32 \% \text { já } \\
\text { tinham usado tubos de ventilação. } \\
\text { - } 57 \% \text { apresentaram patologias no tímpano, como efusões, miringoescleroses, cicatrizes com } \\
\text { tecido atrofiado, retração e perfurações auriculares. } \\
\text { - Anomalias auriculares foram vistas em } 23 \% \text { dos casos, sendo mais comum no grupo } 45, X \text {. } \\
\text { - A análise audiométrica revelou perdas condutivas (gap aéreo - ósseo em } 10 \mathrm{~dB} \text { HL) em } 43 \% \\
\text { e sensorioneurais com uma queda nas frequências médias em } 58 \% \text { das pacientes. } \\
\text { - 4\% usavam aparelhos auditivos. } \\
\text { - Os achados enfatizam a necessidade de exames otológicos e audiológicos regulares nas ST } \\
\text { durante toda a vida. }\end{array}$ \\
\hline 4 & $\begin{array}{l}\text { - Apresenta evidências da ação do cromossomo X na resposta do GH e na perda auditiva } \\
\text { sensorioneural na ST. } \\
\text {-Os achados sugerem que o cromossomo X materno pode expressar um gene ou mais, que } \\
\text { possam influenciar na eficácia do GH, embora a presença do gene autossômico regulador do } \\
\text { crescimento também pode contribuir para o crescimento espontâneo na ST. }\end{array}$ \\
\hline 5 & $\begin{array}{l}\text {-Os índices fisiológicos de estrógeno parecem exercer um possível efeito protetor na audição. } \\
\text {-São necessários mais estudos para comprovar esta hipótese e para selecionar agonistas a } \\
\text { fim de se evitar os efeitos negativos como câncer de mama e útero. }\end{array}$ \\
\hline 11 & $\begin{array}{l}\text {-ST está associada à alta incidência de doenças de orelha média embora também esteja } \\
\text { associada à perda auditiva sensorioneural, sendo esta mais comum na } 20^{\circ} \text { e } 30^{\circ} \text { década de } \\
\text { vida. } \\
\text {-91\% dos pacientes apresentam doenças relacionadas à orelha média com ou sem efusão; } \\
\text {-57\% possuem tubo de ventilação; } \\
\text {-13\% apresentam retração na membrana timpânica; } \\
\text {-22\% possuem perfuração timpânica; } \\
\text {-9\% possuem perda auditiva sensorioneural atribuída à ST. }\end{array}$ \\
\hline 13 & $\begin{array}{l}\text {-Foi observado displasia coclear em um feto de } 13 \text { semanas. } \\
\text {-A análise morfológica falhou ao revelar um padrão alterado da estrutura da cóclea que } \\
\text { pudesse explicar o desenvolvimento da perda sensorioneural, não demonstrando assim um } \\
\text { padrão consistente de malformações na cóclea. } \\
\text {-178 pacientes foram analisados e, desses, } 18 \% \text { apresentavam doenças da orelha média. }\end{array}$ \\
\hline 14 & $\begin{array}{l}\text { - Efusões de orelha média (14,78\%) com retrações de membrana timpânica e/ou perfurações } \\
(10,55 \%) \text { são os achados otoscópicos mais frequentes. } \\
\text { - Seis indivíduos possuiam evidências de colesteatoma, dois pacientes se submeteram à } \\
\text { miringoplastia, seis à timpanoplastia e três à timpanomastoidectomia. } \\
\text { - Os procedimentos de revisão eram comuns. } \\
\text { - A otite media crônica e recorrente é comum em pacientes com ST e o acometimento } \\
\text { frequente leva a múltiplos procedimentos cirúrgicos. } \\
\text {-Quanto mais cedo o uso de PET, menor a necessidade no futuro de procedimentos } \\
\text { timpânicos mais caros. }\end{array}$ \\
\hline
\end{tabular}

\section{Figura 2 - Achados audiológicos na ST}




\begin{tabular}{|c|c|c|c|}
\hline \multirow{2}{*}{ ESTUDO } & A. PRAXIAS & \multicolumn{2}{|c|}{ LINGUAGEM } \\
\cline { 2 - 4 } & $\begin{array}{c}\text { Buco-Faciais e } \\
\text { Articulatórias }\end{array}$ & Receptiva & $\begin{array}{c}\text { Expressiva } \\
\text { The Boston Naming e imagem 5.3 do Boston } \\
\text { Aphasia } \\
\text { Battery. }\end{array}$ \\
\hline 2 & $n c$ & $n c$ & $\begin{array}{c}\text {-Método de avaliação desenvolvido por Belser e } \\
\text { Sudhalter para indivíduos com alterações } \\
\text { desenvolvimentais. } \\
\text {-Análise de diálogos. }\end{array}$ \\
\hline 8 & $n c$ & $n c$ & $\begin{array}{c}\text { INE } \\
\text { INE }\end{array}$ \\
\hline 10 & $n c$ & $n c$ & INE \\
\hline 12 & $n c$ & $n c$ & \\
\hline
\end{tabular}

$\mathrm{PE}^{\star}=$ Protocolo Específico; $\mathrm{PE}^{\star \star}=$ Protocolo Específico

FE: Fala Espontânea; FD: Fala Dirigida

nc: nada consta; INE: instrumento não-especificado

Figura 3 - Avaliações fonoaudiológicas realizadas

\begin{tabular}{|c|c|c|}
\hline \multirow{2}{*}{ Estudo } & \multicolumn{2}{|c|}{ AVALIAÇÃO PSICOLÓGICA } \\
\cline { 2 - 3 } & Cognitiva & Comportamental \\
\hline 5 & QI verbal acima de 95 & Nc \\
\hline 8 & QI verbal acima de 99.2 & N \\
\hline 11 & QI verbal acima de 85 & N \\
\hline 12 & QI vrbal maior que 70 & No \\
\hline 22 & Qi verbal acima de 70 & \\
\hline
\end{tabular}

Nc:nada consta

Figura 4 - Resultados das avaliações psicológicas

\begin{tabular}{|c|c|c|c|c|c|c|c|}
\hline & Alterações encontradas & & & & & & \\
\hline \multirow[t]{5}{*}{$L R$} & & 2 & 7 & 8 & 10 & 12 & 15 \\
\hline & Alt. Memória de trabalho & & & & $x$ & & \\
\hline & Alt. Pocessam. Auditivo & & & & & & \\
\hline & Alt. Compreensão verbal & & & & & & \\
\hline & Alt. Visuo-espaciais & & & & & $x$ & \\
\hline \multirow[t]{11}{*}{$L E$} & Ecolalia & & & & & & \\
\hline & Fala perseverativa & $\mathrm{x}$ & & & & & \\
\hline & Disfluências ou não -fluências & & $x$ & $\mathrm{x}$ & & & \\
\hline & Taquilalia & & & & & & \\
\hline & \begin{tabular}{|l|} 
Discurso incoerente \\
\end{tabular} & & & & & & \\
\hline & Dificuldade em manter tópico de conversação & & & & & & \\
\hline & Desorganização sintática & & & & & & \\
\hline & Inversão pronominal & & & & & & \\
\hline & Simplificações fonológicas & & & & & & \\
\hline & Baixa inteligibilidade & & & & & & \\
\hline & Imprecisão articulatória & & & & & & \\
\hline Praxias & Praxias buco-faciais e articulatórias & & & & & & \\
\hline$T$ & & 1 & 1 & 1 & 1 & 1 & \\
\hline
\end{tabular}

*= resultados não especificados; $T=$ total

Figura 5 - Resultados das avaliações de linguagem receptiva e expressiva e de praxias 


\section{REVISÃO DE LITERATURA}

Muito embora a síndrome de Turner (ST) tenha sido caracterizada por Henry Turner em 1938, muitos estudos ainda se fazem necessários para a melhor compreensão acerca do funcionamento linguístico e comunicativo desta população.

Foram levantados 34 artigos sobre a ST e uma tese dos quais, 15 abordavam características relacionadas ao aspecto fonoaudiológico sendo que: 7 discorriam sobre a audição e suas alterações nesses indivíduos, 6 sobre linguagem receptiva e/ ou expressiva, 5 sobre aspectos cognitivos -analisados de forma indireta- além de 19 artigos sobre as manifestações clínicas em geral.

Nos estudos, foi constatada a freqüente presença de alterações auditivas como as otites médias crônicas e recorrentes ${ }^{(13)}$ que, são em parte explicadas pela presença do palato em ogiva que levaria a distúrbios respiratórios, dificultando a eliminação das secreções o que pode de certa forma facilitar as infecções ${ }^{14}$ bem como necessidade de intervenção cirúrgica. Além de perdas auditivas condutivas e perdas auditivas sensorioneurais que são mais comuns na $20^{\circ}$ e $30^{\circ}$ décadas de vida e que, quando descoberta na fase adulta apresentam rápida progressão, ocasionando presbiacusia precoce. Fish III et al. ${ }^{15}$, analisaram a presença de alterações consistentes na morfologia da cóclea durante o período do desenvolvimento gestacional que possa estar relacionado a ST e, como resultado, verificaram que a análise morfológica falha ao revelar um padrão alterado da estrutura da cóclea que pudesse explicar o desenvolvimento da perda sensorioneural, não demonstrando assim um padrão consistente de malformações.

Apenas o estudo de Gawron et. al. ${ }^{16}$, pesquisou a funcionalidade das Células Ciliadas Externas (CCE) por meio das Emissões Otoacústicas Evocadas Produto de Distorção cujo resultado foi presença de funcionalidade de CCE em 41,4\%. Foi investigada também a resposta das estruturas auditivas por meio do Potencial Evocado Auditivo que estava ausente em $52 \%$ dos participantes. Conforme o mesmo estudo, poucos indivíduos com ST necessitam de aparelhos de amplificação sonora auditiva individual (AASI), sendo que apenas $36 \%$ das participantes apresentaram exames de audiometria tonal alterada sendo que a perda auditiva sensorioneural moderada estava presente em $18 \%$ dos casos, enquanto que $11 \%$ apresentavam perda auditiva condutiva e $5 \%$ perda mista.

Outro estudo ${ }^{17}$ verificou a presença de perda auditiva de origem sensorioneural em apenas 9\% dos indivíduos com ST. Conforme Stemberg et al. ${ }^{18}$, as perdas auditivas de origem condutiva estavam presentes em $43 \%$, sensorioneural em $58 \%$ e $23 \%$ das pacientes com ST apresentaram anomalias auriculares. Foi evidenciada a relação do cromossomo X com a perda auditiva sensorioneural ${ }^{19}$. Outra pesquisa afirma que os índices fisiológicos de estrógeno parecem exercer um possível efeito protetor na audição e como os indivíduos com ST são biologicamente deficientes nesse hormônio apresentam início de presbiacusia mais cedo se comparado à população normal ${ }^{20}$.

Nas avaliações de linguagem junto a esta população, foram relatados episódios de fala perseverativa ${ }^{21}$ porém, o grupo com ST parece evidenciar menor probabilidade de intervenção nas áreas de linguagem e fala do que em outras anormalidades relacionadas ao cromossomo sexual, muito embora apresentem algumas alterações nestas áreas e que podem estar relacionadas as influências do meio externo ${ }^{22}$.

Em seus estudos Temple ${ }^{22}$, referiu bom desempenho das habilidades lingüísticas porém, 4 entre 9 casos avaliados apresentavam déficits nas habilidades expressivas e receptivas, sendo que 3 desses 4 apresentavam QI rebaixado (52, 72 e 73). Dentre as habilidades da linguagem, duas foram classificadas como deficientes: a nomeação automática das cores e de conhecimento lexical e a fluência oral. A possível explicação para o déficit na fluência oral pode ser a presença de déficit generalizado no acesso lexical de certas palavras. $O$ baixo desempenho nas tarefas de fluência oral foi relacionado a dificuldades específicas de evocação e não ao conhecimento lexical que, em geral mostrou-se acima da pontuação do grupo controle. No geral, as habilidades relacionadas à nomeação encontravam-se dentro dos parâmetros da normalidade. Analisando o contexto da performance da fluência nas ST, há indícios de que as palavras das sub-categorias, de alta freqüência no vocabulário ou baixa freqüência que, são de tamanhos normais, apresentam pequenas trocas entre os indivíduos do grupo com ST quando comparadas com a população em geral. O grupo com ST gerou maior proporção de palavras de baixa freqüência. Durante as produções na narrativa as descrições são normais e, no entanto, os testes de narrativa apresentaram certos prejuízos que podem estar atribuídos a um déficit dentro das habilidades de recuperação da execução ou podem representar um déficit na memória episódica ou nos processos executivos que estão relacionados à evocação.

Em geral, os estudos apontam para o nível alto nas habilidades de leitura que envolvem exatidão e compreensão ${ }^{23}$. Segundo Temple e Carney (Apud Mazzocco) ${ }^{24}$, alguns casos de dislexia tem sido 
reportados, porém a sua incidência não é maior que na população em geral e, segundo os mesmos ${ }^{24}$, a hiperlexia também pode estar presente nesse fenótipo.

Analisando as interações sociais, Mazzocco et al., ${ }^{24}$ não verificaram diferenças na comunicação das jovens com ST e sem ST, porém aquelas com ST apresentavam alto índice de "episódios de risos" o que pode denotar ansiedade ou desconforto frente à situação de interlocução.

Episódios de disfluências ${ }^{24},{ }^{22}$, também foram relatados, porém poucas informações estão disponíveis sobre as alterações na fluência se comparados a outras alterações na comunicação em síndromes genéticas ${ }^{25}$.

Os déficits nas habilidades visuo-espaciais estão entre os achados mais recentes e mais consistentes da ST. Mazzoco ${ }^{26}$ realizou levantamento sobre a síndrome e destacou a presença de sinais de déficit da memória visual e pobre organização perceptual, porém os resultados foram controversos. Outro achado mais recente refere-se ao déficit de construção (alteração relacionada à elaboração e execução de estruturas físicas e, quando se trata de habilidades matemáticas, envolvem desde a capacidade de estimar um número aproximado até a decifração de resultados matemáticos) nas crianças com ST que cursam o nível fundamental ${ }^{26}$. Assim, para as crianças menores, o reconhecimento dos símbolos matemáticos pode ser influenciado pela habilidade visuo-espacial; para aquelas na idade escolar, podem ocorrer erros no alinhamento vertical dos números quando nas montagens das operações matemáticas ou outras confusões relativas ao estabelecimento das posições dos algarismos. Nas adolescentes, foram encontrados mais erros no alinhamento das contas no papel e nas tarefas que envolviam o calculo feito "à mão" se comparado aos seus pares.

Conforme Mazzoco, é difícil predizer como os déficits espaciais poderão influenciar no aprendizado matemático e, para poder suprir as dificuldades relacionadas a este aprendizado, novos estudos deverão investigar se esta dificuldade é resultante de prejuízo escolar ou de alteração visuoespacial, além disso é importante averiguar quais são os pontos fortes da criança para potencializar o seu aprendizado.

Em testes cognitivos houve prejuízo na performance dos domínios verbais e espaciais na ST, sendo maior a alteração nas tarefas que demandavam uma memória de trabalho. Estudo comparando as regiões frontoparietais das ST com grupo controle evidenciou que, durante tarefas envolvendo a memória de trabalho visuo- espacial, a ativação contínua esteve significantemente reduzida no grupo ST, o que sugere o papel significante do cromossomo $\mathrm{X}$ no desenvolvimento da circuitaria frontoparietal. Não houve diferenças entre os dois grupos na ativação específica das regiões temporais ${ }^{27}$.

Além de déficits visuo-espaciais os indivíduos com ST podem apresentar dificuldades nas funções motoras para as quais, segundo Ross et al. ${ }^{28}$, a introdução da terapia de estrogênio parece promissora para melhorar o desempenho da velocidade motora e da velocidade do processamento não verbal. Entretanto, outro estudo de Ross et al ${ }^{29}$ (2004), em análise comparativa entre pacientes com falha prematura de ovário, grupo controle e pacientes com ST, constatou que o fenótipo cognitivo das mulheres com falha prematura de ovário e as do grupo controle são similares, porém diferem do grupo com ST, indicando que uma deficiência primária de estrogênio não tem maior impacto na função cognitiva nas mulheres adultas; e as que apresentam uma alteração cognitiva as possuem devido ao fenótipo cognitivo da ST.

A população com ST apresenta maior vulnerabilidade para dificuldades na função social uma vez que são menos engajadas em atividades sociais e possuem poucos amigos. Segundo Suzingan $(2004)^{30}$, em mais da metade dos casos há evidências de dificuldades de interação social, o que de certa forma, está relacionado à timidez, inibições e dificuldades em expressar emoções. Também são relatadas dificuldades em aspectos específicos da cognição social como a compreensão das diferentes faces e dos julgamentos mentais que os envolvem ${ }^{31}$.

As expressões faciais, são importantes sinais sociais e, certas expressões podem estar associadas a diferentes respostas físicas. A amígdala é composta pela porção direita e esquerda e suas hemifaces apresentam funções distintas porém, complementares. Uma das funções da amígdala é o reconhecimento das expressões faciais. Alguns estudos afirmam que há um significante déficit no reconhecimento de expressões faciais de medo nas pacientes com ST ${ }^{32,}{ }^{33}$ e, esse déficit está relacionado à dissociação funcional do lado direito e do lado esquerdo da amígdala, que ocorre quando há uma condição monossômica para o cromossomo $X^{32}$, como por exemplo na ST. O que sugere que a alteração na funcionalidade da amígdala pode ser uma característica neurológica das mulheres com ST que apresentam cariótipo monossômico para o cromossomo X materno $\left(45, X^{\mathrm{m}}\right)^{32}$.

Alguns estudos analisados 5,8,11,12,22 apresentaram como critério de inclusão um QI verbal acima de 70 pontos, porém não foram encontrados estudos relativos a avaliações cognitivas a fim de verificar a 
presença ou ausência de alterações, assim como estudos que analisassem o comportamento de cada genótipo dos indivíduo com ST. Em geral, a deficiência mental não está associada a ST e, segundo Elsheikh et al. ${ }^{34}$, ela está presente naqueles casos que apresentam cariótipo em mosaico que inclui o cromossomo X em anel pequeno. El Abd ${ }^{35}$, que descreve em seu artigo o perfil cognitivo e comportamental de cinco pacientes com cromossomo $X$ em anel (com ou sem deficiência mental), verificou que todos os indivíduos analisados apresentaram um perfil de agressividade, problemas de atenção e impulsividade, além de comportamento de espectro autístico como: limitação da comunicação e comportamento obsessivo compulsivo.

\section{CONCLUSÃO}

A maioria dos estudos sobre a ST encontrados na área fonoaudiológica abordam a subárea da
Audição, ao passo que aqueles referentes aos aspectos práxicos foram os mais escassos. Outros aspectos da ST apresentaram poucos dados ou dados inconsistentes como a escrita, a sintaxe e o perfil psicológico.

É importante ressaltar que existem diferenças individuais que podem gerar resultados variados e com base nessas diferenças, os envolvidos com esta síndrome devem reconhecer sinais indicativos de potencialidades e dificuldades de maneira a promover melhor qualidade de vida para os indivíduos com ST.

\section{AGRADECIMENTOS}

Ao PIBIC (Programa Institucional de Bolsas de Iniciação Científica) e, a todos que contribuíram direta ou indiretamente com o artigo.

\begin{abstract}
Background: genetic syndrome and Speech, Hearing and Language Pathology findings. Purpose: to describe the clinical and speech, hearing and language manifestations in subjects with Turner syndrome. Conclusion: twenty-three articles on Turner' syndrome were collected, of which 7 described hearing and its alterations in these subjects, 6 described the receptive and/or expressive language and praxis, 5 described the psychological and cognitive aspects, besides those, 28 articles referred to the clinical manifestations. Through the literature research it was observed that speech, hearing and language manifestations of Turner syndrome are little studied and, within Speech, Hearing and Language Pathology, hearing manifestations such as hearing loss and ear infections are the most studied, unlike the issues of praxis and language reception/expression.
\end{abstract}

KEYWORDS: Turner Syndrome; Language; Review

\section{REFERÊNCIAS}

1. Jones KN. Síndromes de Anormalidades Cromossômicas -Sindrome X0. In: Jones KN. Padrões Reconhecíveis de malformações congênitas. 5aㅡ edição. São Paulo: Editora Elsevier; 1998., p 81-2.

2. Nielsen J, Wohlert M. Chromosome abnormalities found among 34,910 newborn children: results from a 13-year incidence study in Arhus, Denmark. Hum Genet. 1991;87(1):81-3.

3. Otto, PA; Otto P; Frota - Pessoa O. Aberrações dos cromossomos sexuais - Síndrome de Turner. In: Otto, PA; Otto P; Frota - Pessoa O. Genética
Clinica. 3aㅡ edição. Rio de Janeiro: Editora Francisco Alves; 1978. P. 183-97.

4. Oliveira AW, Freiberger L, Fernandes RD, Marcelino TF, Da Rosa L, Correa M, et al. Síndrome de Turner: relato de caso. Arquivos Catarinenses de Medicina. 2005; 34(3) 76-9.

5. Célia Maria Giacheti. Fonoaudiologia e Genética: Estudos Contemporâneos. In: Beffi-Lopes, DL, S. Tratado de Fonoaudiologia. 1ำ edição. São Paulo: Editora Roca; 2004. p 1040 -54.

6. Dumancic J, Kaic Z, Varga ML, Lauc T, Dumic $\mathrm{M}$, Milosevic SA et al. Characteristica of the craniofacial complex in Turner syndrome. Archives of Oral Biology. 2010; 55 (1):81-8. 
7. Fernandez-Garcia R, Garcia-Doval S, Costoya S, Pasaro E. Analysis of sex chromosome aneuploidy in 41 patients with Turner syndrome: a study of 'hidden' mosaicism. Clin Genet. 2000;58 (3) : 201-8.

8. Wilson RD. Amniocentesis and chorionic villus sampling. Curr Opin Obstet Gynecol. 2000;12(2):81-6.

9. Saenger P, Wilkland KA, Conway GS, Davenport M, Gravholt $\mathrm{CH}$, Hintz R, et al. Recommendations for the diagnosis and management of Turner syndrome. The Journal of Clinical Endocrinology \& Metabolism. 2001; 86 (7):3061-9.

10. Carel JC. Growth hormone in Turner syndrome twenty years after, what can we tell our patients. The Journal of Clinical Endocrinology \& Metabolism. 2005; 90 (6):3793-4.

11. Guimarães MM, Guerra CTG, Alves STF, Cunha MCSA, Marins LA, Barreto LFM et al. Intercorrências clínicas na Síndrome de Turner. Arq Bras Endocrinol Metab. 2001; 45(4):331-8.

12. Gravholt $\mathrm{CH}$, Juul $\mathrm{S}$, Naeraa RW. Morbity in Turner Syndrome. J Epidemiol. 1998;51(2):147-58.

13. Hall JE, Richter GT e Choo DI. Surgical management of otologic disease in pediatric patients with Turner syndrome. International Journal of Pediatric Otorhinolaryngology. 2009; 73(1): 57-65.

14. Lippe BM. Turner Syndrome. In: Sperling MA, ed. Pediatric Endocrinology. Philadephia:WB Saunders Company, 1996(1):387-421.

15. Fish III JH, Schwentner I, Schmutzhard J, Abraham I, Ciorba A, Martini A et al. Morphology studies of the human fetal cochlea in Turner syndrome. Ear \& Hearing. 2009;30(1):143-6.

16. Gawron W, Wikiera B, Rostkowska-Nadolska $B$, Orendorz-Fraczkowska K e Noczynska A. Evaluation of hearing organ in patients with Turner syndrome. International Journal of Pediatric Otorhinolaryngology. 2008; 72(5): 575-9.

17. Parkin $M$ e Walker $P$. Hearing loss in Turner syndrome. International Journal of Pediatric Otorhinolaryngology. 2009; 73(2): 243-7.

18. Stenberg AE, Nyleen $O$, Windh $M$ e Hultcrantz $M$. Problems In Children With Turner' Syndrome. Hearing Research. 1998;124(1-2) 85-90.

19. Hamelin CE, Anglin G, Quigley CA e Deal CL. Genomic Imprinting in Turner syndrome: effects on response to growth hormone and risk of sensorioneural hearing loss. The Journal of Clinical Endocrinology \& Metabolism. 2006;91(8): 3002-10.

20. Hultcrantz $M$, Simonoska $R$ e Stenberg AE. Estrogen and hearing: a summary of recent investigations. Acta Oto-Laryngologica. 2006;126(1): 10-4.
21. Swillen A, Fryns J, Kleczkowska A, Massa G, Vanderschueren-Lodeweyckx M, Van Den Berghe $\mathrm{H}$. Intelligence, behavior and psychological development in Turner syndrome. Genet Couns. 1993;4(1):7-18.

22. Temple $\mathrm{CM}$. Oral fluency and narrative production in children with Turner's syndrome. Neuropsychologia.2002; 40(8):1419-27.

23. Kesler SR. Turner syndrome 2007. Child Adolesc Psychiatr Clin N Am. 2007;16(3):709-22.

24. Mazzocco Mmm, Thompson L, Sudhalter V, Belser RC, Lesniak-Karpiak K e Ross JL. Language use in females with Fragile $X$ or Turner syndrome during brief initial social interactions. Developmental and Behavioral Pediatrics. 2006;27(4): 319-28.

25. Van Borsel J e Tetnowski JA. Fluency disorders in genetic syndromes. Journal of Fluency Disorders. 2007; 32(4):279-96.

26. Mazzocco MMM. Mathematical learning disability in girls with Turner syndrome: a challenge to defining MLD and its subtypes. Developmental Disabilities Research Reviews. 2009; 15(1) 35-44.

27. Hart SJ, Davenport ML, Hooper SR e Belger A. Visuospatial executive function in Turner syndrome: functional MRI and neurocognitive-findings. Brain. 2006;129(5):1125-36.

28. Ross JL, Roeltgen D, Feuillan $P$, Kushner $H$ e Cutler, Jr Gb. Effects of Estrogen on Nonverbal Processing Speed and Motor Function in Girls with Turner's Syndrome. The Journal of Clinical Endocrinology \& Metabolism. 2009; 83 (9): 3198-204.

29. Ross JL, Sandberg DE, Rose SR, Leschek EW, Baron J, Chipman JJ, et al. The effect of genetic differences and ovarian failure: intact cognitive function in adult women with premature ovarian failure versus Turner syndrome. J Clin Endocrinol Metab. 2004;89(4):1817-22.

30. Suzigan LZC. Sindrome de Turner: a perspectiva das pacientes. Jornal de Pediatria. 2004; 80 (4):309-14.

31. Murphy MM. Language and Literacy in Turner syndrome. Top Lang Disorders. 2009; 29 (2): 187-94.

32. Lawrence K, Kuntsi J, Coleman M, Campbell $R$, Skuse D. Face and emotion recognition deficits in Turner syndrome: a possible role for X-linked genes in amygdala development. Neuropsychology. 2003;17(1):39-49.

33. Skuse DH, Morris JS e Dolan RJ. Functional dissociation of amydala-modulated arousal and cognitive appraisal, in Turner syndrome. Brain. 2005;128(9):2084-96. 
34. Elsheikh M, Dunger DB, Conway GS e Wass $\mathrm{JAH}$. Turner 'Syndrome in Adulthood. Endocrine Reviews. 2002; 23(1): 120-40.
35. El Abd S, Patton MA, Turk J, Hoey H, Howlin P. Social, Communicational and behavioral deficits associated withring $X$ Turner Syndrome. Am J Med Genet. 1999; 88 (5)510-6.

http://dx.doi.org/10.1590/S1516-18462011005000081

RECEBIDO EM: 14/12/2010

ACEITO EM: 19/03/2011

Endereço para correspondência:

Suhamy Aline Mandelli

Departamento de Fonoaudiologia da Faculdade de Odontologia de Bauru/ Universidade de São Paulo (FOB/USP)

Alameda Otavio Pinheiro Brizolla 9-75

Bauru - SP - Brasil

CEP: 17012-901

E-mail: s.m.02@hotmail.com 